\title{
Speciation of Inorganic Chromium in Water Samples by ICP-MS Following Low-Temperature Electrothermal Vaporization Using Thenoyltrifluoroacetone as Chemical Modifier
}

\author{
Shizhong Chen ${ }^{* a}$, Shengping $\mathrm{Zhu}^{\mathrm{b}}$, and Dengbo $\mathrm{Lu}^{\mathrm{a}}$ \\ ${ }^{a}$ College of Chemical and Environmental Engineering, Wuhan Polytechnic University, \\ Wuhan 430023, P.R. China \\ ${ }^{b}$ Department of Chemistry, Yunyang Teacher's College, Danjiangkou 442700, Hubei, P.R. China
}

\section{INTRODUCTION}

In recent years, pollution of the environment by heavy metals has become of considerable public and scientific concern due to their extensive use in industry and agriculture. The toxicity, bioavailability, and reactivity of an element depends on its chemical form and concentration $(1,2)$. Chromium is an important element in biological and environmental systems. Cr(III) is considered to be essential for mammals for the maintenance of glucose, protein, and the lipid metabolism, whereas Cr(VI) can cause acute and chronic toxicity in biological systems, even at low concentrations, including have carcinogenic effects (3-6). Therefore, it is necessary to determine the individual species of chromium in different environmental samples.

In order to determine the trace or ultra-trace inorganic chromium species in environmental samples, a chemical separation and preconcentration step is often required prior to analysis. A variety of approaches, including solvent extraction, coprecipitation, ion exchange, cloud point extraction, solid phase extraction, capillary microextraction, and chromatography, have been widely used for the speciation of chromium (7-13).

Recently, interest in adapting electrothermal vaporization (ETV) for sample introduction into the inductively coupled plasma spectrometer (ICP-MS) has consistently received

*Corresponding author.

E-mail: chenshizhong62@163.com

\begin{abstract}
In this work, thenoyltrifluoroacetone (TTA) was used as chemical modifier for the separation and determination of $\mathrm{Cr}$ (III) and $\mathrm{Cr}(\mathrm{VI})$ by low-temperature electrothermal vaporization (LETV) coupled with inductively coupled plasma mass spectrometry (ICP-MS). The proposed method is based on the fact that in the presence of TTA, Cr(III) was quantitatively vaporized and transported from a graphite furnace into the ICP at a relatively low temperature of $900{ }^{\circ} \mathrm{C}$ due to the formation of volatile Cr(III)-TTA chelate, while Cr(VI) was retained in the graphite furnace. Thus, Cr(III) could be separated from $\mathrm{Cr}(\mathrm{VI})$ in the graphite furnace.

The main factors affecting the formation and vaporization of the Cr(III)-TTA chelate were investigated in detail. Under the optimized conditions, the detection limit of $\mathrm{Cr}$ (III) for this method was $0.008 \mathrm{ng} \mathrm{mL}^{-1}$, and the relative standard deviation (RSD) was $4.6 \%\left(\mathrm{c}=1.0 \mathrm{ng} \mathrm{mL}^{-1}\right.$, $\mathrm{n}=9, \mathrm{v}=10 \mu \mathrm{L}$ ). The linear range of the calibration curve spanned three orders of magnitude. The proposed method was applied to the determination of $\mathrm{Cr}$ (III) and Cr(VI) in environmental water samples, with a recovery of 93.5-104\%.
\end{abstract}

attention because of its high sampling efficiency, small sample requirement, low absolute detection limits, and the ability to analyze both liquid and solid samples (14-18). However, some refractory elements, such as $\mathrm{Cr}, \mathrm{Al}, \mathrm{V}, \mathrm{Ti}$, and $\mathrm{Zr}$, are difficult to vaporize either in simple substances or in oxide forms due to their high boiling points. Therefore, the sensitivity of these elements using conventional electrothermal vaporization (ETV) is generally low, and severe memory effects would be encountered.

To solve these problems, the application of various chemical modifiers in ETV-ICP-MS for changing the volatility of the analytes could significantly improve the analytical performance of the method. Representative examples are the application of halogenating reagents $(19,20)$, metal salts $(21,22)$, alkylating reagents $(23,24)$, and chelating reagents (25-27).

Among chemical modifiers, using a chelating reagent as the chemical modifier may offer the following advantages: (a) The vaporization temperature is much lower than in conventional ETV, which prolongs the lifetime of the vaporizer; (b) use of toxic and corrosive reagents such as $\mathrm{Cl}_{2}$ and hydrofluoric acid (HF) could be avoided in routine analysis; and (c) the analytical performance would obviously be improved by combining ETV with a chemical separation/preconcentration. Based on the good volatility and thermal stability, some metal chelates have been employed for vapor-phase sample introduction in inductively coupled plasma atomic emission spectrometry and atomic absorption spectrometry (28-30). So far, however, the application of chelating reagents in ETV for elemental 
speciation has received little attention for use in ICP-MS.

The aim of this work was to explore the feasibility of thenoyltrifluoroacetone (TTA) as chemical modifier for low-temperature ETVICP-MS (LETV-ICP-MS) determination of $\mathrm{Cr}(\mathrm{III})$ and $\mathrm{Cr}(\mathrm{VI})$. The formation conditions and vaporization behaviors of the Cr-TTA chelate were investigated in detail. The proposed method was applied to the determination of $\mathrm{Cr}$ (III) and $\mathrm{Cr}(\mathrm{VI})$ in environmental water samples with satisfactory results.

\section{EXPERIMENTAL}

\section{Instrumentation}

An X-7 ICP-MS system (Thermo Elemental Corporation, USA) was equipped with a modified commercially available WF-4C graphite furnace (Beijing Ruili Instrument Factory, Beijing, P.R. China) and was used as an electrothermal vaporizer for the determination of the analytes. The optimum operating conditions of ETV-ICP-MS are summarized in Table I.

\section{Standard Solutions and Reagents}

A stock standard solution (1.0 $\mathrm{mg} \mathrm{mL}^{-1}$ ) of Cr(III) was obtained from the National Analysis Center of Iron \& Steel (Beijing, P.R. China); Cr(VI) was prepared by dissolving $\mathrm{K}_{2} \mathrm{Cr}_{2} \mathrm{O}_{7}$ (Tianjin Reagent Factory, Tianjin, P.R. China) in deionized water (31). A $0.20 \mathrm{~mol} \mathrm{~L}^{-1}$ TTA solution was prepared by dissolving $4.4440 \mathrm{~g}$ TTA (Shanghai Reagent Factory, Shanghai, P.R. China) in $100 \mathrm{~mL}$ tetrahydrofuran (THF) (Shanghai Reagent Factory, P.R. China). Working solutions were prepared daily from the appropriate dilution of the stock solution. All other reagents used were ultrapure or at least of analytical grade. High purity deionized water $(18.2 \mathrm{M} \Omega)$ obtained with a Milli-Q ${ }^{\circledR}$ A10 system (Millipore
Corporation, Bedford, MA, USA) was used throughout this work.

\section{Procedure}

A $4.0 \mathrm{ng} \mathrm{mL}^{-1} \mathrm{Cr}$ (III) or $\mathrm{Cr}(\mathrm{VI})$ solution and an equal volume of $0.16 \mathrm{~mol} \mathrm{~L}^{-1}$ TTA solution were mixed ( $\mathrm{pH}=4.0$ with $\mathrm{HNO}_{3}$ or $\mathrm{NH}_{3} \cdot \mathrm{H}_{2} \mathrm{O}$ ). After plasma stabilization, $10 \mu \mathrm{L}$ of the resulting solution was pipetted into the graphite tube with a microsyringe. The sample inlet hole was sealed with a graphite rod. Under the selective experimental conditions, the Cr(III)-TTA complex was vaporized and introduced into the plasma at a low temperature of $900^{\circ} \mathrm{C}$ after being dried, while Cr(VI) was still retained in the graphite furnace. Thus, Cr(III) was separated from Cr(VI), and then determined by ICP-MS. The concentration of $\mathrm{Cr}(\mathrm{VI})$ was calculated by the difference between the total concentra-

\section{TABLE I}

Instrumental Operating Conditions for ETV-ICP-MS

\begin{tabular}{|c|c|}
\hline \multicolumn{2}{|l|}{ ICP-MS Plasma } \\
\hline Plasma power & $1300 \mathrm{~W}$ \\
\hline \multicolumn{2}{|l|}{ Flow Rates: } \\
\hline Plasma argon & $14.5 \mathrm{~L} \mathrm{~min}^{-1}$ \\
\hline Auxiliary argon & $0.76 \mathrm{~L} \mathrm{~min}^{-1}$ \\
\hline Nebulizer argon & $0.93 \mathrm{~L} \mathrm{~min}^{-1}$ \\
\hline Sampler orifice (Ni) & $1.1 \mathrm{~mm}$ \\
\hline Skimmer orifice $(\mathrm{Ni})$ & $0.7 \mathrm{~mm}$ \\
\hline Acquisition mode & Peak-jumping \\
\hline Number of sweeps & 100 \\
\hline Dwell time & $10 \mathrm{~ms}$ \\
\hline Acquisition time & $40 \mathrm{~s}$ \\
\hline \multicolumn{2}{|c|}{$\begin{array}{l}\text { Number of measurements } \\
\text { per peak }\end{array}$} \\
\hline Isotopes & ${ }^{52} \mathrm{Cr}$ \\
\hline \multicolumn{2}{|l|}{$\overline{\text { ETV }}$} \\
\hline Sample volume & $10 \mu \mathrm{L}$ \\
\hline Carrier gas flow rate & $0.43 \mathrm{~L} \mathrm{~min}^{-1}$ \\
\hline Drying step & $\begin{array}{r}100^{\circ} \mathrm{C}, \\
10 \mathrm{~s} \text {, hold } 10 \mathrm{~s}\end{array}$ \\
\hline \multicolumn{2}{|c|}{$\begin{array}{r}\operatorname{ramp} 10 \mathrm{~s} \text {, hold } 10 \mathrm{~s} \\
\text { ion step } 900^{\circ} \mathrm{C} \text {, hold } 3 \mathrm{~s}\end{array}$} \\
\hline
\end{tabular}

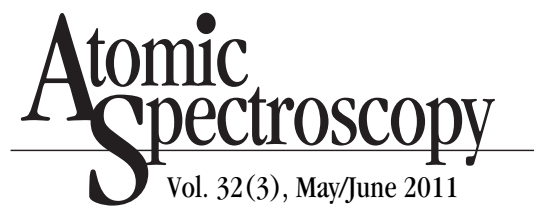

tion of chromium and that of Cr(III). In order to determine the total concentration of chromium, it is necessary to reduce $\mathrm{Cr}(\mathrm{VI})$ to Cr(III) using 99.8\% (v/v) ethanol as the reducing reagent prior to the determination by ICP-MS.

\section{RESULTS AND DISCUSSION}

\section{Investigation of Vaporization Behavior of $\mathrm{Cr}$ (III) and $\mathrm{Cr}$ (VI) with TTA}

The signal profiles of $\mathrm{Cr}$ (III) and Cr(VI) are shown in Figure 1 (A, B, C, D) with and without TTA as the chemical modifier. As can be seen from Figure 1(A), no emission signal of Cr(III) was observed in the absence of TTA. In Figure 1(B), a sharp, intense, and symmetrical signal profile of $\mathrm{Cr}$ (III) was recorded at the comparatively low temperature of $900{ }^{\circ} \mathrm{C}$ after addition of TTA due to the formation of the volatile Cr(III)-TTA complex. In Figure 1(C), the residual signal from 1(B) is very weak, showing that $\mathrm{Cr}$ (III) is vaporized completely with TTA. Figure 1(D) shows that Cr(VI) cannot be vaporized with TTA. From these results, it can be concluded that it is possible to separate $\mathrm{Cr}$ (III) from $\mathrm{Cr}(\mathrm{VI})$ using ETV.

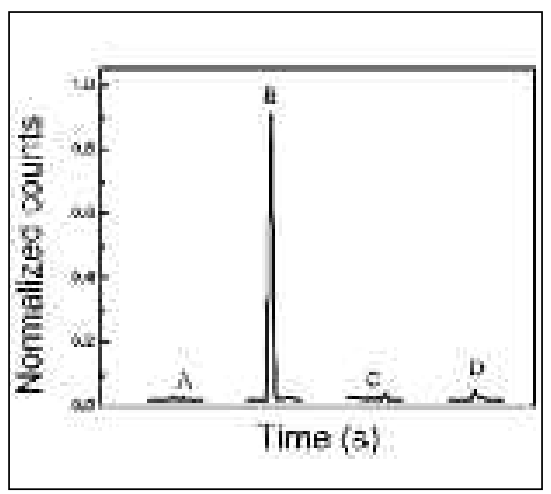

Fig. 1. Signal profiles for Cr vaporized at $900^{\circ} \mathrm{C}$. Vaporization time: $4 \mathrm{~s}$. A: Cr(III) witbout TTA;

B: Cr(III) with TTA;

C: Residual signal from $B$ with TTA;

D: Cr(VI) with TTA. 
It should also be pointed out here that the emission signal of the relative blank solution was not detected in this experiment.

\section{Optimization of Drying Condition}

In the present work, a drying temperature of $100{ }^{\circ} \mathrm{C}$ was used to remove the water and THF from the graphite tube. The signal intensity decreased noticeably when the drying temperature was higher than $200{ }^{\circ} \mathrm{C}$ due to the partial decomposition of the Cr(III)-TTA complex. The effect of drying time on the signal intensity of the analytes was examined with TTA at the drying temperature of $100{ }^{\circ} \mathrm{C}$. The experimental results showed that the drying time has no obvious influence on the signal intensity of $\mathrm{Cr}$ (III) for at least 15 seconds. Thus, a drying temperature of $100{ }^{\circ} \mathrm{C}$ and a drying time of 10 seconds were used in this work.

\section{Selection of Vaporization Parameter}

Figure 2 shows the effects of vaporization temperature on the signal intensity of Cr(III) with and without TTA. It can be seen that without TTA, the signal intensity of
Cr(III) was very weak, could only detected at about $1600^{\circ} \mathrm{C}$, and no signal plateau was obtained by increasing the vaporization temperature to $2600^{\circ} \mathrm{C}$. However, in the presence of TTA, the signal intensity of Cr(III) appeared at about $400{ }^{\circ} \mathrm{C}$, then increased rapidly with the vaporization temperature ranging from $400-800{ }^{\circ} \mathrm{C}$ and reached a maximum and constant signal intensity at $>800{ }^{\circ} \mathrm{C}$. Thus, the vaporization temperature for obtaining the maximum signal intensity is remarkably decreased.

The influence of vaporization time on the signal intensity of Cr(III) was investigated. The results showed that the signal intensity reached the maximum value within 3 seconds after start of the vaporization process. Thus, a vaporization temperature of $900{ }^{\circ} \mathrm{C}$ and 3 seconds as the vaporization time were used for this work.

\section{Effect of TTA Concentration}

The effect of TTA concentration on the signal intensity of $\mathrm{Cr}$ (III) was studied. The results shown in Figure 3 indicate that the signal intensity of Cr(III) strongly depended on TTA concentration. The signal intensity of $\mathrm{Cr}$ (III) (2.0 $\left.\mathrm{ng} \mathrm{mL}^{-1}\right)$ increased remarkably with an increase in TTA concentration. Maximum signal intensity was obtained when the TTA concentration was more than $0.08 \mathrm{~mol} \mathrm{~L}^{-1}$. This concentration is much more than that of $\mathrm{Cr}$ (III) in the graphite furnace. The reasonable mechanism for the experimental fact may be that, on one hand, a large amount of extra TTA favors the formation of the Cr(III)-TTA complex, while, on the other hand, the vapor produced from the extra TTA in the rapid vaporization process suppresses the thermal decomposition of the Cr(III)-TTA chelates. Thus, the concentration of $0.08 \mathrm{~mol} \mathrm{~L}^{-1}$ TTA was used in this work.

\section{Interference of Coexisting Ions}

The effect of some coexisting ions (such as chlorides) on the signal intensity of the analytes was investigated with TTA (seen in Table II). The tolerance amounts of coexisting ions, which give an error less than $10 \%$ for the determination of analyte, were evaluated. For $4.0 \mathrm{ng} \mathrm{mL}^{-1} \mathrm{Cr}$ (III), no significant interferences were observed from the selected metal ions at the maximum amounts tested.

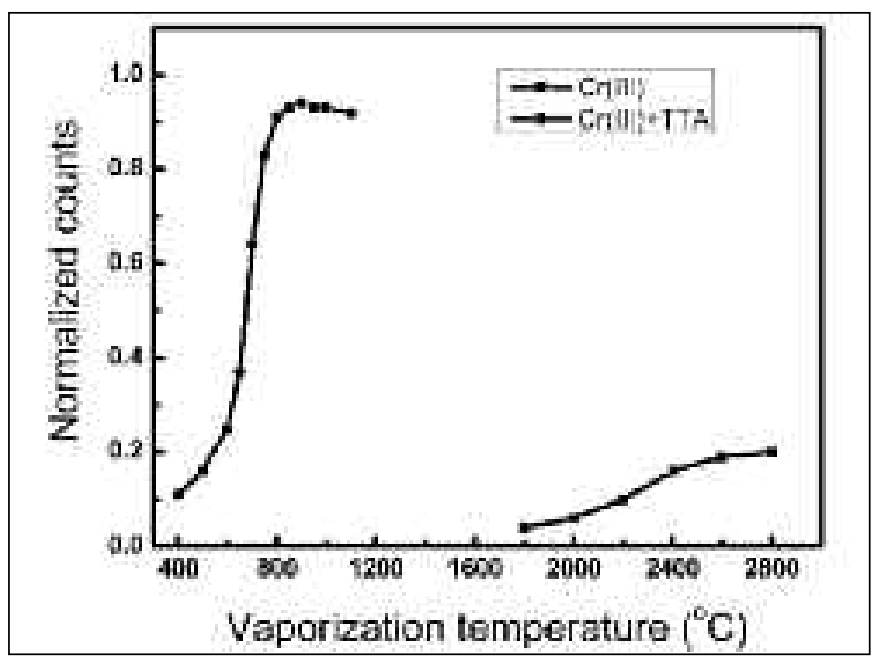

Fig. 2. Influence of vaporization temperature on signal intensity for Cr(III) with TTA.

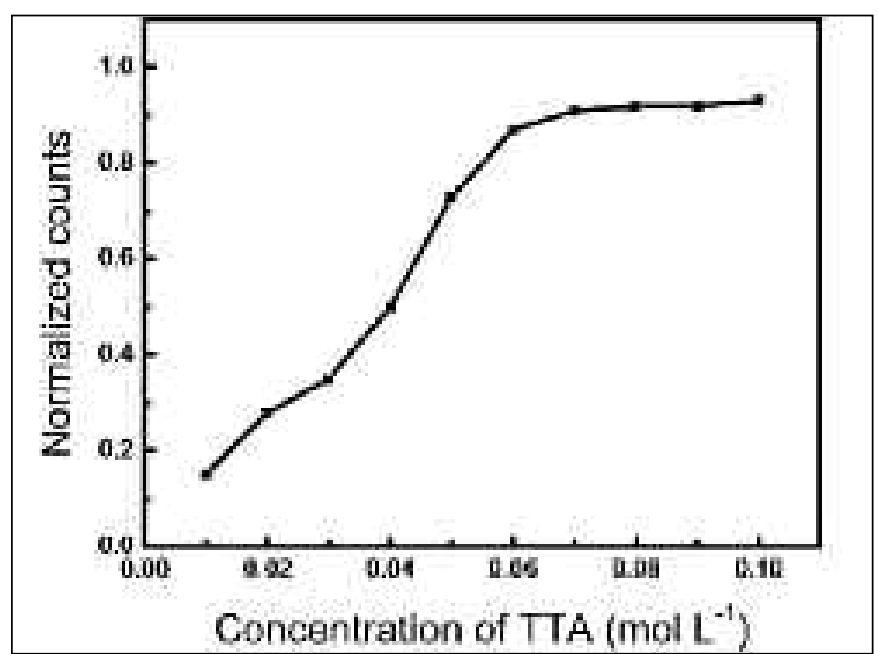

Fig. 3. Effect of TTA concentration on signal intensity for Cr(III). 


\section{Verification of Formation of Cr(III)-TTA Chelate}

In the presence of TTA, as described above, the vaporization behavior of $\mathrm{Cr}$ (III) greatly improved. However, did the system really work as expected. In other words, was the Cr(III)-TTA chelate formed in the ETV, vaporized and transported into the ICP? To answer these questions, the following experiments were performed. At the selected experimental conditions, the ETV was run, as usual, 10 times with a $40-\mu \mathrm{L}$ mixture of $80 \mu \mathrm{g} \mathrm{mL}^{-1} \mathrm{Cr}$ (III) solution and an

TABLE II

Effect of Coexisting Ions in the Determination of $\mathrm{Cr}$ (III)

\begin{tabular}{cc}
\hline $\begin{array}{c}\text { Coexisting } \\
\text { Ion }\end{array}$ & $\begin{array}{c}\text { Concentration } \\
\text { Ratio }\end{array}$ \\
\hline $\mathrm{Na}^{+}, \mathrm{K}^{+}$ & $5000^{\mathrm{b}}$ \\
$\mathrm{Ca}^{2+}, \mathrm{Mg}^{2+}$ & $2500^{\mathrm{b}}$ \\
$\mathrm{Cu}^{2+}, \mathrm{Zn}^{2+}$ & $600^{\mathrm{b}}$ \\
$\mathrm{Fe}^{3+}, \mathrm{Al}^{3+}$ & $300^{\mathrm{b}}$ \\
$\mathrm{PO}_{4}^{3-}, \mathrm{SiO}_{3}{ }^{2-}, \mathrm{SO}_{4}{ }^{2-}$ & $2500^{\mathrm{b}}$ \\
\hline${ }^{\mathrm{a}} \mathrm{Concentration} \mathrm{ratio:}$ & \\
Foreign ion/Cr(III) $=4.0 \mathrm{ng} \mathrm{mL}^{-1}$ \\
${ }^{\mathrm{b}}$ Maximum concentrations tested.
\end{tabular}

equal volume of $0.20 \mathrm{~mol} \mathrm{~L}^{-1}$ TTATHF solution. The sample vapor that was produced was collected in THF. The resulting solution was measured by ultraviolet-visible spectrophotometry (UV-VIS). It was found that its absorption spectrum was very similar with that of the Cr(III)-TTA chelates in THF. These experimental facts demonstrated that Cr(III) was indeed vaporized and transported as Cr(III)-TTA chelates.

\section{Analytical Performances}

The analytical performance of this method was investigated under the optimum experimental conditions. The signal intensity of the analytes was linear with respect to its amount by over three orders of magnitude. The relative standard deviation (RSD) of this method was 4.6\% (n=9, c=1.0 $\left.\mathrm{ng} \mathrm{mL}^{-1}, \mathrm{v}=10 \mu \mathrm{L}\right)$. The detection limit, defined as the amount of analytes that yields a signal three times the standard deviation of the background noise signal intensity, was $0.008 \mathrm{ng} \mathrm{mL}^{-1}$ for Cr(III) with TTA as the chemical modifier.

\section{A A $_{\text {Somic }}^{\text {Spectroscopy }}$}

\section{Sample Analysis}

Water samples, including tap water, lake water and waste water (obtained from Wuhan, P.R. China), were filtered through a $0.25-\mu \mathrm{m}$ membrane filter and stored for future use. The blank was prepared exactly as the samples, except no analytes were added. The proposed method was used for the determination of $\mathrm{Cr}$ (III) and $\mathrm{Cr}(\mathrm{VI})$. The results and recoveries obtained are listed in Table III. The accuracy of the proposed method was examined by analyzing certified reference material GSBZ 5009-88 water sample (obtained from Beijing, P.R. China). The analytical results of this method are in agreement with the certified values.

\section{CONCLUSION}

Thenoyltrifluoroacetone (TTA) was used as the chemical modifier for the separation and determination of Cr(III) and Cr(VI) by lowtemperature electrothermal vaporization inductively coupled plasma mass spectrometry (LETVICP-MS). The experimental results indicate that TTA reacts rapidly with Cr(III) to form a volatile chelate with good stability. The

TABLE III

Analytical Results and Recoveries of Cr(III) and Cr(VI) in Environmental Water Samples

\begin{tabular}{|c|c|c|c|c|c|c|c|}
\hline \multirow[t]{2}{*}{ Sample } & \multicolumn{2}{|c|}{ Added $\left(\mathrm{ng} \mathrm{mL} \mathrm{mL}^{-1}\right)$} & \multicolumn{3}{|c|}{ Found $^{\mathrm{a}}\left(\mathrm{ng} \mathrm{mL}^{-1}\right)$} & \multicolumn{2}{|c|}{ Recovery (\%) } \\
\hline & Cr(III) & $\mathrm{Cr}(\mathrm{VI})$ & Cr(III) & Cr(VI) ${ }^{b}$ & Total & $\mathrm{Cr}(\mathrm{III})$ & $\mathrm{Cr}(\mathrm{VI})$ \\
\hline \multirow[t]{2}{*}{ GSBZ 5009-88 ${ }^{\mathrm{c}}$} & - & - & - & - & $654 \pm 51$ & - & - \\
\hline & 400 & - & - & - & $1048 \pm 64$ & 98.5 & - \\
\hline \multirow[t]{2}{*}{ Tap Water } & 0 & 0 & $1.52 \pm 0.10$ & $0.47 \pm 0.04$ & $1.99 \pm 0.13$ & - & - \\
\hline & 0.5 & 0.5 & $2.03 \pm 0.16$ & $0.95 \pm 0.08$ & $2.98 \pm 0.25$ & 102 & 96.0 \\
\hline \multirow[t]{2}{*}{ Lake Water } & 0 & 0 & $1.34 \pm 0.10$ & $0.83 \pm 0.06$ & $2.17 \pm 0.15$ & - & - \\
\hline & 1.0 & 1.0 & $2.31 \pm 0.15$ & $1.87 \pm 0.14$ & $4.18 \pm 0.31$ & 97.0 & 104 \\
\hline \multirow[t]{2}{*}{ Waste Water } & 0 & 0 & $5.31 \pm 0.45$ & $3.79 \pm 0.27$ & $9.10 \pm 0.62$ & - & - \\
\hline & 4.0 & 4.0 & $9.05 \pm 0.39$ & $7.66 \pm 0.52$ & $16.7 \pm 1.36$ & 93.5 & 96.7 \\
\hline
\end{tabular}

\footnotetext{
${ }^{a}$ Mean value \pm standard deviation: $\mathrm{n}=5$.

b Calculated value.

${ }^{c}$ National reference material (P.R. China), Certified Value of Cr concentration: $640 \pm 36 \mathrm{ng} \mathrm{mL}^{-1}$
} 
Cr(III)-TTA chelate was quantitatively vaporized into the ICP to realize the separation of $\mathrm{Cr}$ (III) from $\mathrm{Cr}(\mathrm{VI})$ at the relatively low temperature of $900{ }^{\circ} \mathrm{C}$. In addition, TTA as the chemical modifier not only effectively prohibits the formation of refractory carbides and eliminates memory effects, but it also greatly promotes the vaporization efficiency and improves the analytical sensitivity due to the formation of the good thermally stable and volatile Cr(III)-TTA complex. The proposed method was applied to the determination of $\mathrm{Cr}$ (III) and $\mathrm{Cr}(\mathrm{VI})$ in environmental water samples with satisfactory results.

\section{ACKNOWLEDGMENTS}

This work was supported by the Provincial Science Foundation of Hubei, P.R. China.

$\overline{\text { Received February 26, } 2011 .}$

\section{REFERENCES}

1. A. Kot and J. Namiesnik, Trends Anal. Chem. 19, 69 (2000).

2. L. Yingjie, $\mathrm{H}$. Bin, and $\mathrm{H}$. Man, Water Res. 42(4-5), 1195 (2008).

3. M. S. El-Shahawi, S. S. M. Hassan, A. M. Othman, and M. A. El-Sonbati, Microchem. J. 89(1), 13 (2008).

4. P. Pazos-Capeáns, M. C. BarcielaAlons, A. Bermejo-Barrera, P. Bermejo-Barrera, A. Fisher, and S. J. Hill, At Spectrosc. 27(4), 107 (2006).

5. M. Tusen and M. Soylak, J. Hazard. Mater. 147, 219 (2007).

6. L. Wang, J. Wang, Z. Zheng, and P. Xiao, J. Hazard. Mater. 177, 114 (2010).

7. B. Áron, K. Roland, and P. József, Microchem. J., 85(1), 103 (2007).

8. L. Wang, B. Hu, Z. Jiang, and Z. Li, Int. J. Environ. Anal. Chem. 82, 387 (2002).

9. A. Parna, M. Sumithra, G. Venkateswarlu, A. C. Sahayam, S. C. Chaurasia, and T. Mukherjee, At Spectrosc. 27(4), 123 (2006).

10. D. M. Geraldo, B. dos R. Edmagno, C. S. C. Antonio, and L.C. F. Sergio, Microchem. J. 92(2), 135 (2009).

11. S. Chen, X. Zhan, D. Lu, and M. Yang, At. Spectrosc. 29(4), 124 (2008).

12. H. Wenling, Z. Fei, and H. Bin, J. Hazard. Mater., 151, 58 (2008).

13. K. Tirez, W. Brusten, A. Cluyts, J. Patyn, and N. D. Brucker, J. Anal. At. Spectrom. 18, 922 (2003).

14. M. Akihiro, O. Shusuke, K. Toshitsugu, H. Bunji, U. Hiroshi, and N. Taketoshi, Microchem. J. 95(1), 85 (2010).

15. R. E. Sturgeon and J. W. Lam, J. Anal. At. Spectrom. 14, 785 (1999).

16. Gil, M. T. C. de Loos-Vollebregt, and C. Bendicho, Spectrochim. Acta Part B 64(3), 208 (2009).

17. L. Xia, X. Li, Y. Wu, B. Hu, and R. Chen, Spectrochim. Acta Part B 63 (11), 1290 (2008).

18. Ó. Mihály, Z. Gyula, and H. Jürgen, Microchem. J. 73(1-2), 125 (2002).
19. M. He, B. Hu, and Z. Jiang, Anal. Chim. Acta 530(1), 105 (2005).

20. U. Schäffer and V. Krivan, Anal. Chem. 710, 849 (1999).

21. A. B. Volynsky and M. T. C. de LoosVollebregt, Spectrochim. Acta Part B 60(11), 1432 (2005).

22. F. G. Lepri, M. B. Dessuy, M. G. R. Vale, D. L. G. Borges, and B. Welz, Spectrochim. Acta Part B 61(8), 934 (2006).

23. S. Tao, Y. Okamoto, and T. Kumamaru, Anal. Chim. Acta 309(1-3), 379 (1995).

24. S. Tao and T. Kumamaru, Anal Chim. Acta 310(2), 369 (1995).

25. S. Chen, H. Zhang, and B. Ruan, At. Spectrosc. 30(4), 143 (2009).

26. Z. Fan, Z. Jiang, F. Yang, and B. Hu, Anal. Chim. Acta 510(1), 45 (2004).

27. S. Tao and T. Kumamaru, J. Anal. At. Spectrom. 11, 111 (1996).

28. S. B. Marilyn, Anal. Chem. 53, 249 (1981).

29. J. R. Castillo, J. Delfa, J. M. Mir, and C. Bendicho, J. Anal. At. Spectrom. 5, 325 (1990).

30. C. H. David and E. P. Edward, Anal. Chem., 47(3), 424 (1975).

31. C. Y. Jimmy, X. Wu, and Z. Chen, Anal. Chim. Acta 436, 59 (2001). 